\title{
Stimulation of regeneration in mammals: pipe dream or realistic goal?
}

\author{
BRUCE M. CARLSON, MD, PhD
}

\begin{abstract}
This article covers a broad spectrum of mammalian regenerative phenomena, including the natural capacity for regeneration of organs and tissues and the classification of mammalian reparative responses. Several broad strategies have been formulated for the stimulation or enhancement of regeneration. Historically, the most common strategy has been to alter the environment surrounding a damaged or regenerating structure. A more contemporary approach to the stimulation of regeneration is the application of cellular engineering principles, which involve strategies such as the implantation of cultured cells, with or without appropriate substrates. Genetic engineering, involving the implantation of genetically engineered cells or the introduction of genes directly into cells in vivo is in the early stages of practical application, although certain laboratory applications have been quite successful. (WOUND REP REG 1998;6:425-433)
\end{abstract}

Two of the traditional holy grails of mammalian regeneration research are to stimulate regeneration of the limb and to stimulate regeneration of the central nervous system. Although these lofty goals have not yet been realized, there has nevertheless been considerable progress in understanding and manipulating mammalian regenerative processes over recent decades. This overview will first review the natural capacities of mammalian tissues and organs to regenerate or to become restored after tissue loss. It will then cover a number of the major strategies used to stimulate or to enhance latent regenerative capacity in mammals.

\section{THE MEANING OF REGENERATION OR RESTORATION}

Simple terminology has often been a barrier in discussions about reparative phenomena in mammals.

From the Department of Anatomy and Cell Biology, University of Michigan, Ann Arbor, Mich.

Reprint requests: Bruce M. Carlson, MD. PhD, Department of Anatomy and Cell Biology, 4643 Medical Sciences /I Building, University of Michigan, Ann Arbor, MI 48709.

Copyright (C) 1998 by The Wound Healing Society.

1067-1927\$5.00+0

\begin{tabular}{|ll|}
\hline BMP & Bone morphogenetic protein \\
EDL & Extensor digitorum longus \\
\hline
\end{tabular}

Many terms imply specific mechanisms, and on some occasions, when a term describing regeneration in a nonmammalian form is applied to mammals, confusion can result.

Restorative processes in vertebrates are commonly broken into four main categories (Table 1). The first is physiological regeneration, which is the maintenance of tissues by replacing cells lost during the course of normal living. Classic examples are the desquamation and replacement of keratinocytes in the epidermis, the generation/loss cycle of intestinal epithelial cells, and the replacement of both red and white blood cells by progeny of stem cells in the marrow.

Reparative regeneration refers to the regeneration of injured or otherwise damaged tissues. Reparative regeneration can occur at several levels. At the cellular level, a classic example is axonal regeneration in a damaged peripheral nerve. The repair of a fractured bone or damaged skeletal muscle is a good example of tissue regeneration that involves several different types of cells. At an even greater level of complexity, the regeneration of a fingertip involves a 
Table 1. Types of restorative processess in mammals

Physiological regeneration
Reparative regeneration
Epimorphic
Tissue
Cellular

Hypertrophy

Compensatory

Regenerative

Functional

Wound healing

variety of tissues, such as skin, bone, connective tissue, and blood vessels. Whether any reparative regenerative process in mammals is a true equivalent to the epimorphic regeneration of an amphibian limb remains to be determined.

Hypertrophy is usually associated with the reactions of internal organs to tissue damage or loss. ${ }^{1}$ Historically, there has been considerable discussion on whether hypertrophy is appropriately classified as a true regenerative response, mainly because cell proliferation and organ growth occur at sites distant from actual tissue damage or loss. Compensatory hypertrophy is usually defined as the growth of one member of a paired organ after a loss or severe damage to the other member. A good example is the enlargement of one kidney after removal of the other. ${ }^{2}$ Regenerative hypertrophy refers to the enlargement of the remaining parenchyma after loss or damage to much of the organ. By far the most prominent example of this is restoration of the liver after partial hepatectomy. ${ }^{3-5}$ A final category of hypertrophy is functional hypertrophy, which is defined as the enlargement of a structure or organ in response to increased functional demands. ${ }^{6}$ Although often considered to be a property of internal organs, functional hypertrophy is also seen in tissues such as skeletal muscle.

The fourth category of restorative process is wound healing, which is often considered to be a biological default mechanism in the event that regeneration does not take place. ${ }^{7}$ Typically, in wound healing, the damage is restored quickly, but the final product differs qualitatively from the original tissue. Wound healing is often interpreted in the regeneration literature as a mechanism that permits survival but sometimes at the expense of full function.

\section{NATURAL REGENERATIVE CAPACITY OF MAMMALS AND STRATEGIES TO STIMULATE THIS CAPABILITY}

Many tissues and organs of mammals have a natural ability to regenerate; many others have only a poor restorative capacity. In some cases, especially among the internal organs, the degree of natural regenerative ability normally attributed to the structure depends on an individual's definition of restoration. Table 2 summarizes the natural restorative abilities of a variety of mammalian tissues or organs. There are species differences in the regenerative ability of some structures. What regenerates well in one species may regenerate poorly in another.

Strategies for stimulating regeneration in mammals fall into several broad categories. Some, such as altering the environment, have been employed extensively in the past. Others, involving cellular implants or artificial substrates, have only recently been employed, whereas genetic engineering remains largely an approach for the future.

Stimulating regeneration in mammals by altering the environment has been the main and most successful approach over the past 40 to 50 years. In a number of cases, the techniques have been applied to humans.

\section{Bone}

One of the earliest successful cases of stimulation of regeneration through altering the environment involved filling in gaps in skull bones. In most mature mammals, including humans, holes created in the skull are not filled in by bone, but rather by softer connective tissue. In the early $1950 \mathrm{~s}$, workers in Polezhaev's laboratory devised a method of regeneration by induction, which involved packing bone sawdust into a defect of the skull over an intact dura mater. ${ }^{89}$ Within days, new spicules of bone were shown to be forming within the defect, and by 2 months after implantation of the bone dust, a strong layer of newly regenerated bone had occurred. According to the theory, the bone sawdust acted as an inducer, with the dura mater facilitating the inductive process. The new osteocytes were thought to arise from immature connective tissue cells that moved into the wound. This technique was applied to humans by the mid-1960s. ${ }^{10}$

Variants of this technique were subsequently described several times, but a major breakthrough came with the experiments of Urist, ${ }^{11}$ which led to the identification of bone morphogenetic protein (BMP) and the ultimate realization that the initial crude prep- 
Table 2. Natural regenerative capacity in mammals

\begin{tabular}{|c|c|c|c|}
\hline \multirow[t]{2}{*}{ Biological structure } & \multirow[t]{2}{*}{ Tissue } & \multicolumn{2}{|c|}{ Regenerative capacity } \\
\hline & & Good & Poor \\
\hline \multirow[t]{7}{*}{ Extremities } & Fingertips & $\mathrm{x}$ & \\
\hline & Antlers & $\mathrm{x}$ & \\
\hline & Ear holes & $\mathrm{x}$ & \\
\hline & Whole digits & & $\mathrm{X}$ \\
\hline & Limbs & & $\mathrm{X}$ \\
\hline & Tails & & $\mathrm{X}$ \\
\hline & & . & \\
\hline \multirow[t]{7}{*}{ Neural Tissue and Sense Organs } & Peripheral nerve & $\mathrm{X}$ & \\
\hline & Taste buds & $\mathrm{X}$ & \\
\hline & Cornea & $\mathrm{x}$ & \\
\hline & Brain, spinal cord & & $\mathrm{x}$ \\
\hline & Retina & & $\mathrm{X}$ \\
\hline & Lens & & $\mathrm{X}$ \\
\hline & Inner ear (hair cells) & & $\mathrm{x}$ \\
\hline \multirow[t]{11}{*}{ Internal Organs } & Liver & $\mathrm{x}$ & \\
\hline & Adrenal cortex & $\mathrm{x}$ & \\
\hline & Salivary glands & $\mathrm{x}$ & \\
\hline & Pancreas (acinar) & $\mathrm{X}$ & \\
\hline & Kidney (hypertrophy) & $\mathrm{x}$ & \\
\hline & Lung (hypertrophy) & $\mathrm{X}$ & \\
\hline & Spleen & $\mathrm{X}$ & \\
\hline & Gonads & & $\mathrm{X}$ \\
\hline & Harderian Gland & & $\mathrm{x}$ \\
\hline & Thyroid (?) & & $\mathrm{X}$ \\
\hline & Pancreas (islets) & & $\mathrm{x}$ \\
\hline \multirow[t]{15}{*}{ Other Structures } & Limb bones & $\mathrm{X}$ & \\
\hline & Ear cartilage & $\mathrm{X}$ & \\
\hline & Skeletal muscle & $\mathrm{X}$ & \\
\hline & Smooth muscle & $\mathrm{x}$ & \\
\hline & Epidermis & $\mathrm{x}$ & \\
\hline & Nipple & $\mathrm{X}$ & \\
\hline & Urinary bladder & $\mathrm{x}$ & \\
\hline & Tendon & $\mathrm{x}$ & \\
\hline & Small blood vessels & $\mathrm{X}$ & \\
\hline & Skull bones & & $\mathrm{x}$ \\
\hline & Articular cartilage & & $\mathrm{X}$ \\
\hline & Cardiac muscle & & $\mathrm{X}$ \\
\hline & Intestine & & $\mathrm{X}$ \\
\hline & Dermis & & $\mathrm{X}$ \\
\hline & Hair & & $\mathrm{x}$ \\
\hline
\end{tabular}


arations contained members of an entire family of growth factors, the BMP family. ${ }^{12}$ Initial experiments showed that BMP has the ability to induce osteogenesis in soft tissues of mammals and led to a variety of experimental approaches and clinical applications of inductive methods of healing defects in bone. ${ }^{13,14}$

Another widely used method of stimulating bone regeneration by altering the environment involves the application of electromagnetic fields to sites of nonhealing fractures. ${ }^{15}$ Such applications soon followed initial experimental work that showed piezoelectric properties of bone and the ability to affect bone growth in experimental animals by applied electric fields. An estimated 250,000 patients with nonhealing fractures (commonly pseudarthroses in fractured tibias) are treated with various electromagnetic field devices.

\section{Cartilage}

Under normal circumstances, articular cartilage regenerates poorly. One technique that has produced some restoration of articular cartilage is to create a defect that extends through the layer of cartilage into the bone. ${ }^{16}$ Osteogenic cells, presumably derived from the marrow, migrate into the defect and produce some cartilage, but the new cartilage has the appearance of fibrocartilage, rather than hyaline cartilage.

\section{Fingertips}

The historical treatment of amputated fingertips is a classic example of how altering the environment inhibits a natural regenerative response. For many decades, the standard surgical treatment of fingertip amputations was to cover the amputation surface with a skin flap. This results in an irregular, bluntended digit. Such treatment mirrors a classic method of inhibiting limb regeneration in salamanders by covering the amputation surface with a skin flap. ${ }^{17}$ After the accidental discovery that children's fingertips amputated distal to the last interphalangeal joint regenerate well, ${ }^{18}$ the standard treatment is protecting the wound surface by bandages and letting natural regenerative processes take over.

\section{Central nervous system}

Although modest axonal regeneration can occur in certain central nervous system tracts (e.g., adrenergic pathways), most regions of the mammalian brain and spinal cord are characterized by minimal or no regeneration of severed axons. One of the most important experimental and conceptual breakthroughs occurred when Bray et al. ${ }^{19}$ devised the model of suturing a segment of peripheral nerve onto the end of a severed central tract, for example, the optic nerve. Remarkable growth of central axons occurred within the grafts, but when regenerating neural processes reached the end of the graft, elongation ceased because the environment of the central nervous system distal to the graft was incapable of sustaining axonal growth. Extracellular matrix molecules, such as laminin and Schwann cell-derived growth factors, are important environmental conditions that facilitate axonal growth within the peripheral nerve segments, ${ }^{20}$ but much work remains to identify specific environmental features that promote axonal outgrowth within the central nervous system.

\section{Neural retina}

The damaged neural retina of mammals does not regenerate, but in certain amphibian species, for example, many newts, an essentially complete neural retina can regenerate from the pigment epithelial layer of the retina. ${ }^{21}$ Although successful retinal regeneration has not been accomplished in mammals, regeneration of the neural retina in chick embryos has been stimulated by adding a source of basic fibroblast growth factor to the vitreous body after removal of the retina ${ }^{22}$ In vitro, as well, retinal pigment epithelial cells of birds have been shown to transdifferentiate into neural retina if exposed to basic fibroblast growth factor and certain conditions of aggregation. ${ }^{23}$

\section{Skeletal muscle}

For many years, skeletal muscle was assumed to have a poor capacity for reparative regeneration. Although in certain circumstances, such as transverse incisions, muscle regeneration is inhibited by excessive scar formation, it is now well recognized that under other conditions muscle fibers regenerate well. ${ }^{24}$

An instructive example of the importance of the environment as a determinant of the success of a regenerative process involves the influence of aging on skeletal muscle regeneration in the rat. ${ }^{25}$ After autotransplantation, extensor digitorum longus (EDL) muscles regenerate 2.5 to 3.0 times more poorly in 2year-old rats than in 4-month-old rats, as measured by maximum tetanic force of mature regenerates. The success of regeneration of this muscle can be dramatically changed through a cross-age transplantation procedure. If a muscle from an old rat is transplanted into the bed of the EDL muscle of a young rat, the old muscle regenerates as well as a young muscle. Conversely, if an EDL muscle from a young rat is grafted into an old host, it regenerates no better than an old 
muscle autograft. Subsequent research on this model has indicated that a significant environmental factor is the degree of success of reinnervation of the muscle grafts, which is much poorer in old than in young rats. ${ }^{26,27}$

\section{Limb}

Stimulating limb regeneration in mammals has challenged investigators for many years. The healing of amputated mammalian digits has been described by Neufeld. ${ }^{28}$ After amputation of either limbs or proximal digits, the amputation surface undergoes epithelialization, often beneath a scab. In contrast to amputated amphibian limbs, relatively large segments of the damaged tissues in the distal stump often become necrotic and are ultimately cleared by phagocytic processes. Large numbers of spindleshaped mononuclear cells typically accumulate beneath the wound epidermis, but they go on to form a highly cellular pad of fibrous connective tissue across the plane of amputation. Little removal of distal bone occurs, but a collar of subperiosteal cartilage typically forms in the area. Through a process of constriction and wound healing, full-thickness skin eventually covers the amputation surface. Neither tissue dedifferentiation nor blastema formation occurs in amputated mammalian extremities.

Virtually all of the techniques that have been used to try to stimulate limb regeneration in mammals were first applied to postmetamorphic anuran amphibians. Early attempts to stimulate postmetamorphic anuran limb regeneration commonly involved applying mechanical or chemical trauma to the surface of newly amputated limbs. ${ }^{9}$ Such methods produced only minimal effects on amputated mammalian extremities. ${ }^{9,29}$ Similarly, hyperinnervation has been applied to amputated frog and mammalian limbs..$^{30,31}$ Retrospective analysis of the results of such experiments has strongly suggested that the initial reports of stimulation of limb regeneration were overly optimistic. Whereas some outgrowth was obtained, the "regenerates" consisted principally of poorly organized nodules of cartilage and other tissue elements rather than the well-patterned products of epimorphic regeneration. Another approach that has been used to stimulate limb regeneration in both frogs and mammals is electrical stimulation. ${ }^{32}$ The general principle behind this approach has been based on the hypothesis that limb regeneration in frogs and mammals is unsuccessful because the appropriate bioelectrical environment (e.g., the level of current outflow from the amputation stump) is deficient. Most attempts to stimulate regeneration have consisted of implanting battery packs in the animals and leading electrodes into the limbs to restore missing current or potential differences. The best results have been reported when the cathode has been situated distalmost in the limb stump. Under these conditions, outgrowths similar to the type seen after nerve deviation have been reported. Although these outgrowths are usually poorly organized, the presence of induced skeletal elements with epiphyseal platelike structures has been reported.$^{33}$ Even the presence of an epiphyseal plate is not evidence of the occurrence of epimorphic regeneration, because such structures can form in bony nodules formed after simple trauma to tendons in rats. ${ }^{34}$ We do not understand the mechanism underlying the formation of such structures, and it underscores how poor our current understanding is of mammalian regenerative processes.

Some fundamental questions remain to be answered before meaningful progress can be made in stimulating limb regeneration in mammals. First and foremost is whether the individual tissues of the limb retain the capacity to participate in an epimorphic regenerative process. Is this capacity lost? Is it retained but somehow masked? Is the capacity present but not able to be expressed because integrative processes are absent or out of phase?

One way to approach this issue at the level of individual tissues is to create mosaics by combining tissues from limbs that do not regenerate with limbs that do. In amphibians, this was done by covering stumps of freshly amputated axolotl limbs with skin from nonregenerating postmetamorphic frog limbs. Frog epidermis covered the wound surface of the axolotl limbs and permitted normal-appearing dedifferentiation, blastema formation, and the differentiation of early digital primordia before the frog epidermis was displaced by axolotl epidermis. ${ }^{35}$ This study demonstrated that the epidermis of a postmetamorphic frog limb retains the capacity to support normal limb regeneration. Attempts to create mosaics with other limb tissues of frogs and axolotl limb stumps were not successful.

A persistent problem in attempts to stimulate limb regeneration in mammals is whether a putative regeneration blastema in a mammalian limb can be equated with the regeneration blastema of a urodele limb. It is apparent that morphology alone is not sufficient to answer such a question. A comparison of patterns of gene expression between urodele regeneration blastemas and other putative blastemas may provide a better level of discrimination. 


\section{REGENERATION BY TISSUE ENGINEERING WITH CELLULAR IMPLANTS OR ARTIFICIAL SUBSTRATES}

For the regeneration of structures and organs through tissue-engineering approaches, several conditions must be met. First is a source of cells, and second is a substrate on which the cells can grow and proliferate. Third is a means of getting the structure to grow, whether in vivo or in vitro so that it can attain a dimension that would allow it to become fully functional in the body. Finally, the engineered structure or organ must become biologically reintegrated with the body, a function that would in most cases involve vascularization and often innervation.

\section{Cellular implants}

The rationale behind using cellular implants is to replace cells that are missing, incapable of dividing, or diseased with a population of cells that will ultimately attain the mass and functional properties of the missing or damaged tissue. Three examples will serve to illustrate these applications.

A seemingly straightforward application is the use of implanted chondrocyte precursors in the repair of defects in the articular cartilage of the knee. In adult cartilage, a defect is not filled by the proliferation of chondrocytes along the edge of the lesion. Several laboratories have developed techniques in which cultured chondrocytes or their precursors are implanted into a defined lesion created within articular cartilage. ${ }^{36}$ The implanted chondrocytes produce morphologically normal matrix and restore the articular surface. The chondrocyte implantation technique has been applied to humans, ${ }^{37}$ but the long-term success rate is not yet clear. The inductive methods of Polezhaev for repairing defects in the skull by induction have recently been complemented by the implantation of cultured periosteal cells into the defects. ${ }^{38}$

One of the most highly publicized cellular implantation methods is the implantation of neuronal precursor or other types of cells into the central nervous system for the treatment of diseases, such as Parkinsonism. ${ }^{39}$ The most common technique has been to transplant human fetal dopaminergic brain tissue from the substantia nigra into the substantia nigra of patients. ${ }^{40}$ More recently, the transplantation into the brain of cultured cells that have been transfected with a gene of interest has been performed in rodents. ${ }^{41}$ The critical features of current brain transplantation techniques are integration of the transplanted cells with those in the surrounding brain tissue and the production and release of substances to augment those that are produced in insufficient quantities in the host brain.

A third application of cellular implantation techniques is myoblast transfer into existing muscles. This technique was initially devised as a form of cellular engineering to supplement the reduced functional muscle mass in individuals afflicted with muscular dystrophy, ${ }^{42}$ but it has also been considered to be a method for gene therapy by introducing genetically altered myoblasts into muscles. ${ }^{43,44}$ The principle behind the use of myoblast transfer for the treatment of muscular dystrophy is the augmentation of the supply of myogenic precursor cells (satellite cells), which are presumed to be exhausted in severe cases of muscular dystrophy. In Duchenne muscular dystrophy, the muscle fibers break down because of the absence of dystrophin, a subsarcolemmal protein that imparts mechanical strength to the muscle fiber. After a number of rounds of muscle fiber breakdown and subsequent regeneration, the success of regeneration becomes less, and the muscle as a whole is considerably weakened. In myoblast transfer, satellite cells from normal muscles are harvested; the population is expanded in vitro, and the myoblasts are injected into a dystrophic muscle. Within the host muscle, the transferred normal myoblasts both proliferate and become incorporated into multinucleated muscle fibers. Myoblast transfer has significantly improved the mass and function of host muscles in dystrophic mice, ${ }^{45,46}$ however, the results of human trials have been disappointing. ${ }^{47,48}$

\section{Substrates}

For many cases of assisted regeneration in mammals, especially in the case of significant tissue loss, it is necessary to provide a substrate upon which implanted cells can attach and grow. For example, a number of early attempts to replace removed muscles by implanting large numbers of myoblasts failed, probably because of a lack of attachment sites. Substrates must have a variety of characteristics in order to be appropriate for application in attempts to regenerate tissues or organs. First, the substrate must be of a material and have the appropriate physical properties to serve as an attachment site for the cells that will serve as the basis for regenerating the tissue or organ. For some tissues, such as skeletal structures or blood vessels, the original artificial substrate may remain as a permanent part of the regenerated structure, but for other tissues, especially if growth is involved, it is important for the original substrate to 
be resorbed and replaced by natural biological materials. Another important characteristic of any substrate is that it not interfere with processes, such as vascularization or innervation, that allow the regenerating structure to become integrated with the body.

\section{Size considerations}

For the replacement of missing tissue by bioengineered tissue, the final size is an important consideration. In practical terms, a significant mass of regenerated or engineered tissue is often necessary in order to provide a functional replacement. Two general strategies are to engineer a structure so that at the time of implantation it is of the required size and to implant a mixture of cells and substrate that would allow growth to provide the needed functional mass and possibly shape, as well.

An excellent example of the former approach is the engineering of a polymer/chondrocyte construct into the shape of a human ear and its implantation into the back of a nude mouse ${ }^{49}$ During their residence in the mouse, the chondrocytes of the construct form a cartilage matrix so that the artificial ear has both the shape and structure of an ear. Thus formed in a biological host, the artificial ear could then be implanted onto a human host.

In order to allow growth within the host, it is necessary to implant cells that have a significant proliferative potential. A potentially important application for this approach would be the engineering of secretory tissues, a good example being pancreatic islets. ${ }^{50}$ In this case, the form is not as important as secretory function.

\section{Reintegration with the body}

For any type of engineered tissue or structure, complete structural and functional integration with the body is the ultimate goal. With the exception of cartilage and epithelial sheets, vascularization is an essential early integrative event. This can be a significant limitation on the size of implanted tissue, because most cells will not survive for more than a few hours if they are separated from a direct blood supply by a distance of more than a few hundred microns, at most. Strategies for vascularization include implanting engineered tissue constructs in small enough or thin enough pieces so that the cells contained in them can survive by diffusion until vascular sprouts can grow in to them. At this point, regenerative growth could potentially be the mechanism for increasing the tissue mass. Another possibility to be explored is to create vascular channels in an ex vivo engineered structure so that an immediate functional vascular connection could be made at the time of implantation. This would require a level of tissue technology that has not been reported to date.

For any innervated structure, neural integration is also necessary. In the case of engineered muscles, motor nerves would have to have access to and be able to make connections with every muscle fiber. Whether the innervation required for proprioceptive function could ever be successfully established remains an open question. Especially if muscle fibers are grown in an artificial microtubular scaffolding, prior to or just after implantation of myoblasts, the substrate would either have to be resorbed by the time motor nerve sprouts reach the muscle fibers or the material would have to possess the properties of the normal junctional basal lamina and allow a functional synapse to become established. For neural transplants into the brain, functional connections with appropriate neurons in the brain of the host would be the normal desired end result. In this case, however, the problem is somewhat simpler than is the case for muscle, because the synaptic connections would likely be made by neural processes growing out from the implant into surrounding brain tissue.

For many tissues, mechanical integration with the host is of primary importance. This is especially true of supporting tissues, in which the interface between implanted material (cells and their substrate in the case of regenerative tissue engineering) and host tissue is of paramount importance. For reconstructing or regenerating whole muscles, tendon connections must be established in order for the regenerating muscle to develop properly and to produce a mechanically effective contractile response. ${ }^{34}$ In the case of vascular prostheses, tissue continuity is the most important consideration, but the wall of the regenerated vessel must develop mechanical properties that resist the formation of aneurysms.

\section{SUMMARY}

Stimulation of regeneration in mammals has been a tough nut to crack, but over the past several decades, considerable progress has been made. In stimulating pure regeneration, most advances have occurred by providing potentially regenerating tissues an environment that is compatible with regeneration. Notable examples are regeneration in the central nervous system, skeletal muscle, bone, and fingertips. The application of tissue-engineering approaches, including implants of normal or genetically engineered precur- 
sor cells, has produced a number of successes, with skin replacement being one of the most successful applications of these principles. Genetic engineering stands on the horizon as the next breakthrough area to be explored.

\section{REFERENCES}

1. Liozner LD, editor. Compensatory hypertrophy of the organs of mammals (Russian). Moscow: State Publishing House for Medical Literature, 1963.

2. Goss RJ, Nowinski WW, editor. Compensatory renal hypertrophy. New York: Academic Press, 1969.

3. Fausto N, Webber EM. Liver regeneration. In: Arias IM, Boyer JL, Fausto N, Jakoby WB, Schachter DA, Shafritz DA, editors. The liver: biology and pathobiology (3rd ed). New York: Raven Press, 1994.

4. Columbano A, Shinozuka $H$. Liver regeneration versus direct hyperplasia. FASEB J 1996;10:1118-28.

5. Michalopoulos GK, DeFrances MC. Liver regeneration. Science 1997;276:60-6.

6. Goss RJ. Adaptive growth. New York: Academic Press, 1964.

7. Stocum DL. Wound repair, regeneration and artificial tissues. Austin, TX: R.G. Landes, 1995.

8. Matveeva AI. Regeneration of dog skull vault bone after trauma. Biol Sci 1958;119:181-5.

9. Polezhaev LV. Organ regeneration in animals. Springfield, IL: Charles C. Thomas, 1972.

10. Strebkov VS. Experiment of application of the method of destruction according to L.V. Polezhaev with the goal of regeneration of bone in regions of defects of the skull. In: Polezhaev $\mathrm{LV}$, editor. Conditions of regeneration of organs and tissues in animals (Russian). Moscow, 1966:277-81.

11. Urist MR. Bone: formation by autoinduction. Science 1965;150:893-9.

12. Urist MR, Huo YK, Brownell AG, Hohl WM, Buyske J, Lieze A, Tempest P, Hunkapillar M, Delange RK. Purification of bovine bone morphogenetic protein by hydroxyapatite chromatography. Proc Natl Acad Sci USA 1984;81:371-5.

13. Rosen V, Theis RS. The BMP proteins in bone formation and repair. Trends Genet 1992;8:97-102

14. Reddi AH. Role of morphogenetic proteins in skeletal tissue engineering and regeneration. Natl Biotech 1998;16:247-52.

15. McGinnis ME. The nature and effects of electricity in bone. In: Borgens RB, Robinson KR, Vanable, JW Jr, McGinnis ME, editors. Electric fields in vertebrate repair. New York: Alan R. Liss, 1989:225-84

16. Campbell CJ. The healing of cartilage defects. Clin Orthop Rel Res 1969;64:45-63.

17. Godlewski E. Untersuchugen über auslösung und hemmung der regeneration beim axolotl. Roux Arch 1928;114:108-43.

18. Illingworth CM. Trapped fingers and amputated finger tips in children. Pediatr Surg 1974;9:853-8.

19. Bray GM, Villegas-Perez MP, Vidal-Sanz M, Carter DA Aguayo AJ. Neuronal and nonneuronal influences on retinal ganglion cell survival, axonal regrowth, and connectivity after axotomy. Ann NY Acad Sci 1991;33:214-28.

20. Aguayo AJ, Rasminsky M, Bray GM, Carbonetto S, McKettacher L, Villegas-Perez MP, Vidal-Sanz M, Carter DA. Degenerative and regenerative responses of injured neurons in the central nervous system of adult mammals. Phil Trans $R$ Soc Lond B 1991;331:337-43.

21. Stroeva OG, Mitashov VI. Retinal pigment epithelium: proliferation and differentiation during development and regeneration. Int Rev Cytol 1983;83:221-93.
22. Noji S, Matsuo T, Koyama E, Yamaai T, Matsuo N, Taniguchi S. Expression pattern of acidic and basis fibroblast growth factor genes in adult rat eyes. Biochem Biophys Res Commun $1990 ; 168: 343-9$

23. Pittack C, Jones M, Reh TA. Basic fibroblast growth factor induces retinal pigment epithelium to generate neural retina in vitro. Development 1991;113:577-88.

24. Mauro A, editor. Muscle regeneration. New York: Raven Press, 1979.

25. Carlson BM, Faulkner JA. Muscle transplantation between young and old rats: age of host determines functional recovery. Am J Physiol 1989;256 (Cell Physiol;25):C1262-6.

26. Carlson BM, Faulkner JA. The regeneration of noninnervated muscle grafts and Marcaine-treated muscles in young and old rats. J Gerontol 1996;51:B43-9.

27. Carlson BM, Faulkner JA. Muscle regeneration in young and old rats: effects of motor nerve transection with and without Marcaine treatment. J Gerontol 1998;53A:B52-7.

28. Neufeld DA. Digital regeneration in mammals. In: Hall BK, editor. Fracture repair and regeneration. Boca Raton, FL: CRC Press, 1992:287-312.

29. Schotté OE, Smith CB. Wound healing processes in amputated mouse digits. Biol Bull 1959;117:546-61.

30. Singer $M$. Induction of regeneration of the forelimb of the postmetamorphic frog by augmentation of the nerve supply. $J$ Exp Zool 1954;126:419-72.

31. Bar-Maor JA, Gitlin G. Attempted induction of forelimb regeneration by augmentation of nerve supply in young rats. Transpl Bull 1961;27:460-1.

32. Borgens RB. Natural and applied currents in limb regeneration and development. In: Borgens RB, Robinson KR, Vanable JW Jr, McGinnis ME, editors. Electric fields in vertebrate repair. New York: Alan R. Liss, 1989:27-75.

33. Smith SD. The role of electrode position in the electrical induction of limb regeneration in sub adult rats. Bioelectrichem Bioenergetica 1981;8:661-70.

34. Carlson BM. The regeneration of minced muscles: monographs in developmental biology (Vol. 4). Basel: S. Karger AG, 1972:130.

35. Carlson BM. The regeneration of axolotl limbs covered by frog skin. Dev Biol 1982;90:435-40.

36. Grande DA, Pitman MI, Peterson L, Menche D, Klein M. The repair of experimentally produced defects in rabbit articular cartilage by autologous chondrocyte transplantation. J Orthop Res 1989;7:208-18.

37. Brittberg M, Lindahl A, Nilsson A, Ohlsson C, Isaksson O, Peterson L. Treatment of deep cartilage defects in the knee with autologous chondrocyte transplantation. N Engl J Med 1994;331:889-95.

38. Breitbart AS, Grande DA, Kessler R, Ryaby JT, Fitzsimmons RJ, Grant RT. Tissue engineered bone repair of calvarial defects using cultured periosteal cells. Plast Reconstr Surg 1998;101:567-74.

39. Lindvall $O$, Widner $H$, Rehncrona $S$, Brundin $P$, Odin $P$, Gusavii B, Frackowiak R, Leeders KL, Sawle G, Rothwell JC, et al. Transplantation of fetal dopamine neurons in Parkinson's disease: one-year clinical and neurophysiological observation in two patients with putaminal implants. Ann Neurol 1992;31:155-65.

40. Fine A. Human fetal tissue research: practice, prospects and policy. Cell Transplant 1994;3:113-45.

41. Fisher Lo, Gage FH. Grafting in the mammalian central nervous system. Physiol Rev 1993;73:583-616.

42. Law PK, Goodwin TG, Fang Q, Quinley T, Vastagh G, Hall T, Jackson T, Deering MB, Duggirala V, Larkin C, Florendo JA, Li LM, Yoo TJ, Chase N, Neel M, Krahn T, Holcomb RL. Human gene therapy with myoblast transfer. Transplant Proc $1997 ; 29: 2234-7$. 
43. Katpati G, Ascadi G. The potential for gene therapy in Duchenne muscular dystrophy and other genetic muscle diseases. Muscle Nerve 1993;16:1141-53.

44. Yao SN, Kurachi K. Expression of human factor IX in mice after injection of genetically modified myoblasts. Proc Natl Acad Sci USA 1992;89:3357-61.

45. Law PK, Goodwin TG, Li HJ. Histocompatible myoblast injection improves muscle structure and function of dystrophic mice. Transplant Proc 1981;20:1114-9.

46. Karpati G, Pouliot Y, Zubryzycka-Gaarn E, Carpenter S, Ray PN, Worton RG, Holland P. Dystrophin is expressed in $\mathrm{mdx}$ skeletal muscle fibers after normal myoblast implantation. Am J Pathol 1989;135:27-32.

47. Tremblay JP, Malouin RR, Huard J, Bouchard JP, Satoh A, Richards CL. Results of a triple blind clinical study of myo- blast transplantations without immunosuppressive treatment in young boys with Duchenne muscular dystrophy. Cell Transplant 1993;2:99-112.

48. Mendell JR, Kissel JT, Amato AA, King W, Signore L, Prior TW, Sahenk Z, Benson S, McAndrew PE, Rice R, et al. Myoblast transfer in the treatment of Duchenne's muscular dystrophy. N Engl J Med 1995;333:823-38.

49. Cao Y, Vacanti J, Paige KT, Upton J, Vacanti CA. Transplantation of chondrocytes utilizing a polymer-cell construct to produce tissue-engineered cartilage in the shape of a human ear. Plast Reconstr Surg 1997;100:297-302.

50. Kendall DM, Robertson RP. Pancreas and islet transplantation in humans. Diabetes Metab 1996;22:157-63. 